\title{
Urban Design Strategy from the Perspective of Low-Carbon City Planning
}

Wei Qian*

Suzhou Art \& Design Technology Institute, Suzhou 215000, China. E-mail: qwmonica0821@163.com

\begin{abstract}
The economy growth has improved the development of cities. In cities' continuous development and construction process, carbon emissions are also gradually increasing, causing serious environmental pollution and energy shortage. At present, low-carbon urban planning and design has become the demand of contemporary urban construction, and sustainable low-carbon economy has become the inevitable choice of urban planning. Based on this, this article briefly introduces the concept of low-carbon city planning and the principles of urban design from the perspective of low-carbon city. By analyzing the existing problems in current urban planning, this article proposes urban design strategies from the view of low-carbon city planning, seeking to make contributions to the improvement of urban planning levels.
\end{abstract}

Keywords: Low-Carbon Concept; Urban Planning; The Design Strategy

\section{Introduction}

With China's economic growth and the continuous development of science and technology, the people have put forward higher requirements on life qualities. In addition to the severe threat of global energy shortage and environmental damage, nowadays, the planning and construction of low-carbon cities have become important goals that cannot be ignored in modern economic and social growth. The concept of low-carbon city has been well known and accepted by the people. At the present stage, incorporating low-carbon city planning into urban design is an important thought in China's urban design, which aims to make reasonable planning for cities under the concept of low-carbon economy and to ultimately promote the improvement of the overall quality of China's urban environment ${ }^{[1]}$.

\section{Low-carbon city planning}

\section{concept}

Low-carbon city planning refers to integrating low-carbon concept into urban planning and construction, reducing urban carbon emissions, and alleviating the high carbon emissions in cities. Low-carbon city planning involves a wide range and cannot be defined from one aspect. The author holds that low-carbon city planning is usually designed and planned from economic conditions, development mode, lifestyle, urban operation system and many other aspects through literature review. The theoretical starting point of low-carbon city emerged in the UK. Through the connection between spatial planning and low-carbon planning, the theory was fully applied to urban planning and Belton zero-ecological community was established ${ }^{[2]}$. Japan followed the UK in 2004 and many articles were written on low-carbon society and the impact of climate warming on urban planning, as well as many energy-saving measures in

\footnotetext{
Copyright (C) 2020 Wei Qian

doi: 10.18686/utc.v6i1.79

This is an open-access article distributed under the terms of the Creative Commons Attribution Non-Commercial License

(http://creativecommons.org/licenses/by-nc/4.0/), which permits unrestricted non-commercial use, distribution, and reproduction in any medium, provided the original work is properly cited.
} 
urban planning

\section{Principles of urban design from the perspective of low-carbon city planning}

\subsection{Economics of low-carbon city design}

For all urban construction and planning, the economic basis must be considered firstly. Therefore, the design and implementation of low-carbon cities must pay attention to the principle of economy and the leap of creating value for cities. Therefore, in design of low-carbon city, it is necessary to combine low-carbon sustainable economic development with the principle of energy conservation and emissions reduction to realize the resource utilization and to maximize the economic benefits from various aspects. To make the concept of low-carbon city into fully effect, it is also needful to realize resource utilization and the growth of the economic interests while protecting the city production and living environment.

\subsection{Flexibility in low-carbon city design}

The design and construction of low-carbon cities should take some time to establish standard systems and models to adapt to the flexibility of social changes. Therefore, sustainable development of low-carbon city design requires reasonable planning, deployment and use of urban resources to meet people's demands for life qualities, ecological environment and sustainable development.

\subsection{Low-carbon city design is sustainable}

Cities are part of the natural environment. Therefore, the low-carbon design of cities should focus on the design principle of sustainable development. When designing a city, its natural environment must be combined with functions of regeneration, automatic purification and sustainable development. In urban construction and population activities, emphasis must be placed on the integration with the natural environment to ensure the sustainable development of a low-carbon urban environment ${ }^{[3]}$.

\section{Problems in urban planning}

With the acceleration of urbanization in China, urban planning and construction are also developing rapidly. There are many problems in current situation.

\subsection{Strict zoning of urban land}

In the process of urban planning, areas for commerce, the residents and industries are clearly divided into a single functional group separated by main roads or green belts. Through this method, it can effectively reduce the impact of industrial production on the daily life, and create a unified image of the city, but may also have a scale effect, resulting in long commutes, increased traffic demand and road traffic pressure, resulting in increased carbon emissions.

\subsection{Large road network spacing}

The building density of each block in the city is relatively average, which can quickly form the urban road network layout. However, high road network density will affect traffic flow and reduce road network efficiency, while high building accuracy may make it difficult to build efficient public transport hubs. In order to improve the density of the road network, some cities are gradually increasing the width of the road, making it more difficult for pedestrians to cross the road, thus reducing the frequency of pedestrians and bicycles, which is inconsistent with the concept of a low-carbon city.

\subsection{Unreasonable layout of urban green space ecosystem}

In the current urban planning, the green land rate index is very large, but it is mainly concentrated in some gateway areas, such as urban parks and both sides of main roads, creating a good image of the city. The relatively marginal areas of the city lack green space, which affects the ecological environmental protection effect of the city.

\section{Urban design strategy from the perspective of low-carbon city planning}

\subsection{Relevant departments timely improve China's low-carbon environmental protection of the relevant legal system}

Attaching importance to relevant laws and 
regulations is not only a necessary guarantee for the implementation of relevant national policies, but also an effective measure to promote the development of low-carbon concept. Firstly, we need to integrate China's laws, policies and regulations, such as the Energy Conservation Law, the Renewable Energy Law and other energy laws related to environmental protection laws ${ }^{[4]}$. Only the correct understanding and application of existing laws and regulations can ensure that the direction of urban planning work is consistent with its policies. Secondly, relevant state departments should timely improve laws and regulations on low-carbon energy utilization. With China's rapid economic development, relevant departments need to timely improve and supplement relevant policies and regulations, and regularly monitor and supervise the work of urban planning departments. Only by establishing and improving the legal guarantee mechanism related to low-carbon economic development, formulating fiscal and tax incentives, and improving the urban legal system related to low-carbon economic growth can we accumulate experience and technology and gradually establish our own urban low-carbon development mechanism.

\subsection{Accelerate the construction of low-carbon city evaluation system}

An appropriate assessment system is the standard to measure the low-carbon level of a city and the foundation for the healthy development of a low-carbon city. Therefore, it is very important to accelerate the establishment of a scientific evaluation system for low-carbon cities. First, make a carbon inventory that matches the state of the city. Second, work out how to calculate carbon emissions. The basic yield analysis method is the basis for comparing carbon emission levels between cities. Third, establish a final carbon statistics system. At present, China has not established the final carbon emission statistical system, and the statistical data is not perfect. Therefore, it is necessary to establish the carbon emission statistical system and database as soon as possible.

\subsection{Highlight characteristic ecological city image}

\subsubsection{Urban landscape sequence control}

The spatial form of urbanization under the guidance of ecology should avoid repetition and pay attention to the organization of various landscape elements to create spatial order and rich and varied cities. In all urban design, we can make full use of traditional garden landscape methods, such as borrowing scenes and landscapes for design. At the same time, humanitarian needs, such as road access and security, need to be considered.

\subsubsection{Preserve the natural landscape}

Natural landscape includes mountains, rivers, forests and other natural scenes, as well as historical and cultural factors. These landscapes balance with the survival of some plants and animals in the city, so it is necessary to preserve the natural landscape and realize the sustainable development of man and nature. In addition, modern planning and design should pay close attention to the interaction and integration of local landscape and modern urban landscape.

\subsubsection{Urban contour shape shaping}

As a kind of "edge" of the city, the skyline is a reflection of the city's facade and distant landscape. While paying attention to the skyline formed by the building entities, urban design must also fully protect the urban ecological environment ${ }^{[5]}$.

\subsection{Optimize the layout of urban space}

\subsubsection{Promote the compact and multi-center development of urban development}

The research community has reached consensus on the ideal model of low-carbon cities, that is, the planning and design of low-carbon cities should be based on compact cities. Compact city is a new concept of urban construction based on the actual conditions and requirements of urban construction. From the perspective of low-carbon city construction, the advantage of compact city is that it can effectively optimize the city's public transportation system, greatly reduce transportation costs; it can also improve the life cycle of urban infrastructure, and make comprehensive use of land and urban resources.

Urban low-carbon development is related to urban density and spatial structure. Nowadays, energy-intensive cities are dominated by low-density buildings and cars, and the overall impact of carbon emissions from traffic is huge. If urban planning 
can achieve a perfect and compact combination of office, entertainment and residential functions, it will reduce the number and distance of travel of citizens. Therefore, unnecessary travel can be realized by comprehensively developing urban functional areas and restricting the use of some land to realize the compact and multi-center development of the city.

\subsubsection{Improve the public transport system to reduce the use of private cars}

By combining the spatial form of the central city with the public transport system of the city, the goal of low-carbon development is realized. At the same time, it is necessary to pay attention to strengthen the construction of intelligent transportation system. In the current rapid development of information technology, urban traffic system must also realize highly intelligent, such as electronic police, real-time monitoring system, remote control, in order to fast and timely deal with all kinds of daily traffic. For example, traffic efficiency can be significantly improved through automatically traffic lights adjustment, or traffic rules enforcement according to the practical traffic flow on the road.

\subsection{Plan the road system well}

In urban planning, road traffic system planning includes many different road layouts, functions and section designs. As the basic framework of urban development, road network directly determines the form of urban space. It has to do with urban development and citizens' daily commutes. Systematic road planning is critical to reducing carbon emissions in transport. When designing the road system, we must ensure good road grade configuration, reduce unnecessary congestion, and add branches in the central city and residents to facilitate low-carbon travel for residents. In the design of road sections, the current traffic conditions of the city should be taken into account, and the future traffic demand distribution should be predicted to meet the guiding demand and ensure the rationality and reliability of the road system. At the same time, good road greening can not only bring beautiful scenery on the city streets, but also increase the traffic flow and improve the travel environment. In addition, the roadside trees can also isolate the sound between the street and the road ahead, allowing people working and living in the building to fully enjoy their lives.

\subsection{Reasonable design of municipal facilities}

The main application of low-carbon concept in urban municipal design is discussed as follows. Firstly, low-carbon fuel can be used for power and heating in the application of power resources and heating system, such as wind power and solar energy; Secondly, to plan heating roads to reduce energy losses caused by long-distance transport. Thirdly, in the urban sewage treatment system, the location of municipal waste treatment plants should be set reasonably to ensure the shortest distance between them and the municipal waste source to shorten the transportation time of sewage and reduce energy consumption.

\section{Conclusion}

In short, it is imperative to incorporate low-carbon concepts into current urban planning and design. Therefore, in the future urban construction, the planning of urban road system, spatial layout, municipal facilities, ecological environment and other aspects should be paid more attention to. In order to gradually improve China's urban low-carbon development mechanism, it is also necessary to integrate the concept of low-carbon economy, establish and improve the evaluation system of low-carbon economy.

\section{References}

1. $\quad$ Fang C. Urban planning for building low-carbon cities (in Chinese). Journal of Green Science and Technology 2010; (7): 182-184. doi: 10.3969/j.issn.1674-9944.2010.07.076.

2. Zhao $X$. On the urban planning of building low-carbon cities (in Chinese). China Interior Decoration \& Renovation World 2017; (10): 131.

3. Qi W. Urban planning education based on low carbon cities. The Guide of Science \& Education 2011; (21): 5-6.

4. Wang L, Chen Y. Exploration of urban planning measures for low-carbon city construction (in Chinese). Scientific Research 2017; (2): 293.

5. Dong Q, Zhen F. Guidance analysis of low-carbon city concept to urban planning (in Chinese). Urban Development Studies 2010; 17(8): 152-155. doi: 10.3969/j.issn.1006-3862.2010.08.026. 